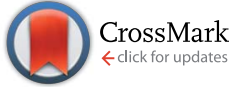

Cite this: RSC Adv., 2017, 7, 5813

Received 1st December 2016 Accepted 29th December 2016

DOI: $10.1039 / c 6 r a 27628 h$

www.rsc.org/advances

\section{Large electrocaloric strength and broad electrocaloric temperature span in lead-free $\mathrm{Ba}_{0.85} \mathrm{Ca}_{0.15} \mathrm{Ti}_{1-x} \mathrm{Hf}_{x} \mathrm{O}_{3}$ ceramics}

\author{
Xiangjian Wang, ${ }^{a}$ Jiagang Wu, ${ }^{\mathrm{b}}$ Brahim Dkhil, ${ }^{\mathrm{c}}$ Chunlin Zhao, ${ }^{\mathrm{b}}$ Tangyuan $\mathrm{Li}^{,}{ }^{\mathrm{a}}$ Wei $\mathrm{Li}^{\mathrm{a}}$ \\ and Xiaojie Lou*ad
}

The electrocaloric (EC) effect of $\mathrm{Ba}_{0.85} \mathrm{Ca}_{0.15} \mathrm{Ti}_{1-x} \mathrm{Hf}_{x} \mathrm{O}_{3}$ (abbreviated as: $\mathrm{BCTH}$ ) ceramics has been systematically investigated using an indirect method. Our results indicate that the $\mathrm{BCTH}_{0.06}$ ceramic exhibits a sharp ferroelectric-paraelectric phase transition, around which a large EC value of $1.03 \mathrm{~K}$ is obtained under the electric field of $35 \mathrm{kV} \mathrm{cm}^{-1}$, associated with a relatively broad electrocaloric temperature span. The giant EC strength of the $\mathrm{BCTH}_{0.06}$ ceramic is $0.29-0.31 \mathrm{~K} \mathrm{~mm} \mathrm{kV}^{-1}$ under an external electric field of 9 to $35 \mathrm{kV} \mathrm{cm}^{-1}$, which is larger than most previous values. The temperature of the EC peak shifts to higher temperature as the electric field increases, which implies that electric field may be another powerful tool to obtain a large EC value and modulate the EC peak. The ceramics with higher $\mathrm{Hf}$ contents display a strong diffusive character. The $\mathrm{BCTH}_{0.15}$ ceramic shows a relatively small EC strength (0.10-0.13 $\mathrm{K} \mathrm{mm} \mathrm{kV}^{-1}$ ) with a broader EC temperature span. The diffusive feature of the $\mathrm{BCTH}_{x}$ ceramics with high $\mathrm{Hf}$ concentrations broaden the electrocaloric temperature span and meanwhile decrease the EC strength considerably. Our results indicate that compositional modification in $\mathrm{BaTiO}_{3}$-based ceramics offers a promising route for designing potential dielectric cooling materials with excellent EC properties.

\section{Introduction}

Recently, the exploration of new types of solid-state refrigeration has attracted considerable attention due to the risks associated with greenhouse gas emissions and the urgent need for next-generation solid-state cooling devices., ${ }^{\mathbf{1 , 2}}$ Promising candidates for solid-state refrigeration that have triggered extensive studies recently are mainly focused on caloric materials, especially electrocaloric (EC) materials. ${ }^{2-4}$ In EC materials, the EC effect results from the temperature change induced by the change in polarization of dielectric materials via the application/removal of the electric field under adiabatic conditions. In 2006, A. S. Mischenko et al. ${ }^{2}$ reported a giant EC value of $12 \mathrm{~K}$ at $480 \mathrm{kV} \mathrm{cm}{ }^{-1}$ in $\mathrm{PbZr}_{0.95} \mathrm{Ti}_{0.05} \mathrm{O}_{3}$ films of $350 \mathrm{~nm}$ in thickness. This work has stimulated many researchers to explore the EC effect in inorganic and organic materials. ${ }^{3,5-18}$ It is well known that large EC values could be readily achieved at thin films, due to their high breakdown field. For instance,

${ }^{a}$ Multi-disciplinary Materials Research Center, Frontier Institute of Science and Technology, State Key Laboratory for Mechanical Behavior of Materials, Xi'an Jiaotong University, Xi'an, China.E-mail:xlou03@mail.xjtu.edu.cn

${ }^{b}$ Department of Materials Science, Sichuan University, 610064, China

'Laboratoire Structures, Propriétés et Modélisation des Solides, CentraleSupélec, CNRS-UMR 8580, Université Paris-Saclay, ChâtenayMalabry Cedex 92295, France

${ }^{d}$ MOE Key Laboratory for Nonequilibrium Synthesis and Modulation of Condensed Matter, Xi'an Jiaotong University, Xi'an 710049, China a giant EC value of $45.3 \mathrm{~K}$ was obtained in relaxor $\mathrm{Pb}_{0.8} \mathrm{Ba}_{0.2} \mathrm{ZrO}_{3}$ thin films with the coexistence of antiferroelectric and ferroelectric phases at room temperature by Peng et al. ${ }^{8}$ Unfortunately, the lower heat capacity of thin films hinders their application in medium and large-scale solid-state cooling devices. Recently, bulk EC materials have been extensively studied to enhance their EC values. These include $\mathrm{BaTiO}_{3}$ based single crystals, ${ }^{3,19}$ ceramics, ${ }^{7,20,21} \mathrm{Bi}_{0.5} \mathrm{Na}_{0.5} \mathrm{TiO}_{3}$-based ceramics ${ }^{6,22-24}$ and $\mathrm{K}_{0.5} \mathrm{Na}_{0.5} \mathrm{NbO}_{3}$-based ceramics. ${ }^{25}$ The $\mathrm{BaTiO}_{3}$ based materials are considered favorably as suitable EC materials due to their relative low and tunable Curie temperature, low coercive field and lead-free character. However, it remains as a big challenge for scientists to further increase EC temperature change up to $2 \mathrm{~K}$ for commercial usage in $\mathrm{BaTiO}_{3}$-based ceramics due to their relative lower breakdown field. In the past few years, it was suggested that a good way to enhance the EC effect of the ceramic is to construct a morphotropic phase boundary through compositional modifications. The piezoelectric, electromechanical and electrocaloric properties of the ceramics are enhanced significantly, which is attributed to the comparable energy in the energy landscape at the coexistence of multi-phases. ${ }^{7}$ Based on this theory, large EC values have been achieved using this theory in $(1-x) \mathrm{BaTi}_{0.8} \mathrm{Zr}_{0.2} \mathrm{O}_{3}-x \mathrm{Ba}_{0.7} \mathrm{Ca}_{0.3^{-}}$ $\mathrm{TiO}_{3}$ ceramics, ${ }^{26} \mathrm{BaTi}_{1-x} \mathrm{Sn}_{x} \mathrm{O}_{3}$ ceramics ${ }^{7}$ and $\mathrm{Ba}_{0.94} \mathrm{Ca}_{0.06} \mathrm{Ti}_{1-x^{-}}$ $\mathrm{Sn}_{x} \mathrm{O}_{3}$ ceramics. ${ }^{20}$ For $(1-x) \mathrm{BaTi}_{0.8} \mathrm{Zr}_{0.2} \mathrm{O}_{3}-x \mathrm{Ba}_{0.7} \mathrm{Ca}_{0.3} \mathrm{TiO}_{3}$ ceramics, the best EC properties were achieved for $x=0.30$ by Bai et $a .^{27}$ and $x=0.4$ by Zhou et $a .^{28}$ respectively. Such 
discrepancy may be related to the grain size of ceramic and compositional fluctuations. To date, the mechanism underlying the electrocaloric effect is not yet fully established. ${ }^{\mathbf{1}}$ In addition, the magnitude of electric field is significant element to influence the EC effect. High electric field in ceramics may induce significant Joule heating, ${ }^{29,30}$ breakdown and fatigue which hinder their future application in efficient EC cooling. EC strength $\eta(\eta=\Delta T / \Delta E)$ is another important parameter to characterize EC effect in different materials. Generally speaking, large EC temperature are achieved at higher electric field, provided that the ceramic does not suffer electrical breakdown. On the other hand, EC strength has been observed to decrease at higher electric field using indirect or direct method in $\mathrm{BaTiO}_{3}$-based ceramics, ${ }^{20,21,31}$ and $0.45 \mathrm{BaZr}_{0.2} \mathrm{Ti}_{0.8^{-}}$ $\mathrm{O}_{3}-0.55 \mathrm{Ba}_{0.7} \mathrm{Ca}_{0.3} \mathrm{TiO}_{3}$ single crystal. $^{19}$ The decreasing EC strength is attributed to phase transition from the first-order to more diffusive second-order under higher electric field. ${ }^{20}$ Kutnjak et al. studied the EC effect using high-resolution calorimeter, their results indicate that the maximum of EC strength is occurred at electric field critical point in lead-based ceramic relaxors ${ }^{32}$ and $\mathrm{BaTiO}_{3}$ single crystal. ${ }^{33}$

Previous results suggest that the diffuse or relaxor phase transition in $\mathrm{PbMg}_{1 / 3} \mathrm{Nb}_{2 / 3} \mathrm{O}_{3}-x \mathrm{PbTiO}_{3}$ relaxors ${ }^{29,32,34,35}$ and $\mathrm{BaZr}_{0.2} \mathrm{~T}_{0.8} \mathrm{O}_{3}$ relaxor ceramic ${ }^{21}$ broadens the electrocaloric temperature peak span, and is favorable for future refrigeration applications. However, it remains as a big challenge to design EC materials withstanding high electric field. It is highly warranted to enhance EC effect under low electric field. Therefore, it is desirable to study systemically the relationship between EC effect and the magnitude of electric field. Previous studies ${ }^{36,37}$ indicate that the compositional modification of $\mathrm{B}$-site in $\mathrm{BaTiO}_{3}$ ceramic modulates the nature of phase transition. Here, the EC effect of $\mathrm{Ba}_{0.85} \mathrm{Ca}_{0.15} \mathrm{Ti}_{1-x} \mathrm{Hf}_{x} \mathrm{O}_{3}$ ceramics is studied at various electric fields using thermodynamics Maxwell relations. Our results show that the largest $\mathrm{EC}$ value of $1.03 \mathrm{~K}$ is obtained at 35 $\mathrm{kV} \mathrm{cm}{ }^{-1}$ in the $\mathrm{BCTH}_{0.06}$ ceramic, associated with a giant EC strength of $0.29-0.31 \mathrm{~K} \mathrm{~mm} \mathrm{kV}^{-1}$ under an external electric field of 9 to $35 \mathrm{kV} \mathrm{cm}{ }^{-1}$. The $\mathrm{BCTH}_{0.15}$ ceramic with strong diffuse character exhibits broad electrocaloric temperature range associated with relatively low EC strength.

\section{Experimental}

The $\mathrm{Ba}_{0.85} \mathrm{Ca}_{0.15} \mathrm{Ti}_{1-x} \mathrm{Hf}_{x} \mathrm{O}_{3}(x=0.06,0.10,0.125$, and 0.15) ceramics were fabricated by conventional solid state method as described elsewhere. ${ }^{38}$ The ceramics were coated with silver pastes on the upper and bottom surfaces and sintered at $600{ }^{\circ} \mathrm{C}$ for $10 \mathrm{~min}$ for electrical measurements. The crystal structures of all ceramics were examined using X-ray diffraction (XRD Shimadzu 7000). The density of all the ceramics was measured using Archimedes methods. The dielectric measurements were conducted with a HIOKI 3532 LCR meter from $-100{ }^{\circ} \mathrm{C}$ to $180{ }^{\circ} \mathrm{C}$. The ferroelectric hysteresis loops $(P-E)$ were measured at different electric fields and temperatures using Radiant precise workstation at $10 \mathrm{~Hz}$. Heat flow analysis of these ceramics was conducted by a differential scanning calorimeter (DSC, TA Instruments Q200).

\section{Results and discussion}

The room temperature XRD patterns of $\mathrm{BCTH}_{x}$ ceramics are shown in Fig. 1. These ceramics show a pure perovskite phase without secondary impurity phase, indicating that $\mathrm{Ca}^{2+}$ and $\mathrm{Hf}^{4+}$ ions have diffused into the $\mathrm{BaTiO}_{3}$ lattice to form $\mathrm{Ba}_{0.85}$ $\mathrm{Ca}_{0.15} \mathrm{Ti}_{1-x} \mathrm{Hf}_{x} \mathrm{O}_{3}$ solid solution. The splitting of the (200) and (310) peaks exist the mixture of tetragonal and monoclinic phase in the $\mathrm{BCTH}_{006}$ ceramics. The overlapping of the diffraction peak around $45^{\circ}$ at $x>0.10$ indicates that the structure transforms from tetragonal phase to pseudocubic one.

To investigate the phase transition behavior of $\mathrm{BCTH}_{x}$ ceramics, their dielectric constants as a function of temperature were collected at $10 \mathrm{~Hz}, 100 \mathrm{~Hz}, 1000 \mathrm{~Hz}, 10000 \mathrm{~Hz}$ and $100000 \mathrm{~Hz}$ and $1 \mathrm{~V}$ during cooling process, as shown in Fig. 2. The Curie temperature of all the ceramics decreases successively with increasing of $\mathrm{Hf}$ contents, it changes from $T_{\mathrm{c}}=$ $104{ }^{\circ} \mathrm{C}(x=0.06)$ to $T_{\mathrm{c}}=55{ }^{\circ} \mathrm{C}(x=0.15)$. The dielectric permittivity peaks of the ceramics become broader at higher $\mathrm{Hf}$ contents, which indicates the existence of a compositioninduced diffuse ferroelectric phase transition. It was found that the frequency dispersion of dielectric permittivity of $\mathrm{BCTH}_{0.15}$ ceramic becomes obvious, indicating that the phase transition indeed becomes more diffuse.

In order to further present diffuseness character of the phase transition in these ceramics, the modified the Curie-Weiss law $^{39,40}$ are suggested to determine the diffuse exponent $\gamma$, as follows: $1 / \varepsilon-1 / \varepsilon_{\mathrm{m}}=\left(T-T_{\mathrm{m}}\right)^{\gamma} / C$, where $\varepsilon_{\mathrm{m}}$ is the maximum of dielectric constant and $T_{\mathrm{m}}$ is the corresponding temperature. $\gamma$ and $C$ are assumed to be constant. Fig. 3 shows the plot of $\ln (1 / \varepsilon$ $\left.-1 / \varepsilon_{\mathrm{m}}\right)$ as a function of $\ln \left(T-T_{\mathrm{m}}\right)$ of $\mathrm{BCTH}_{x}$ ceramics at $10000 \mathrm{~Hz}$. For $\gamma=1$, a normal Curie-Weiss law is satisfied, and $\gamma=2$ means a complete diffuse phase transition to relaxor behavior. The diffuse exponent $\gamma$ is found to be $\sim 1.65,1.81,1.85$ and 1.95 for $\mathrm{BCTH}_{x}$ ceramics with $x=0.06, x=0.10, x=0.125$ and $x=0.15$, respectively. The diffuseness of these ceramics is affected by the competition between $\mathrm{Hf}^{4+}(0.71 \AA)$ and $\mathrm{Ti}^{4+}(0.61$ $\AA)$ cations occupied in B-site of perovskite in nature. In addition, previous study has also reported that the sintering

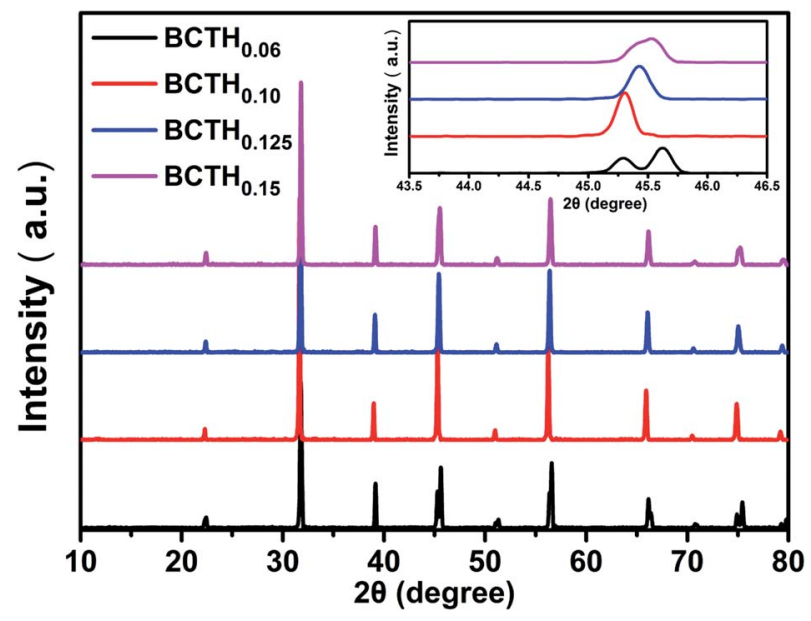

Fig. 1 Room temperature XRD patterns of $\mathrm{BCTH}_{x}$ ceramics. 

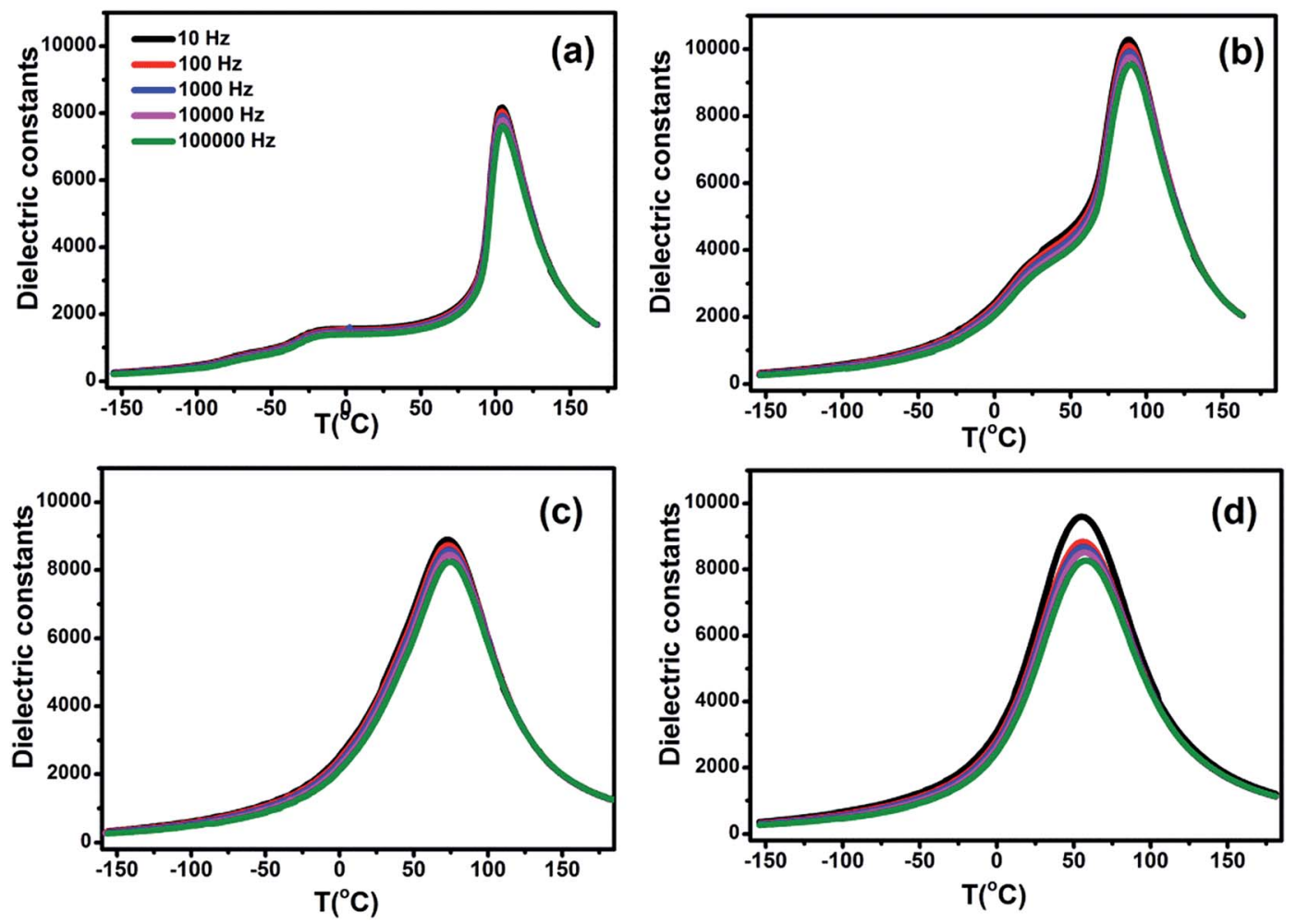

Fig. 2 The dielectric constants of $\mathrm{BCTH}_{x}$ (a) $x=0.06$, (b) $x=0.10$, (c) $x=0.125$, (d) $x=0.15$ ceramics as a function of temperature at $10 \mathrm{~Hz}$, $100 \mathrm{~Hz}, 1000 \mathrm{~Hz}, 10000 \mathrm{~Hz}$ and $100000 \mathrm{~Hz}$.

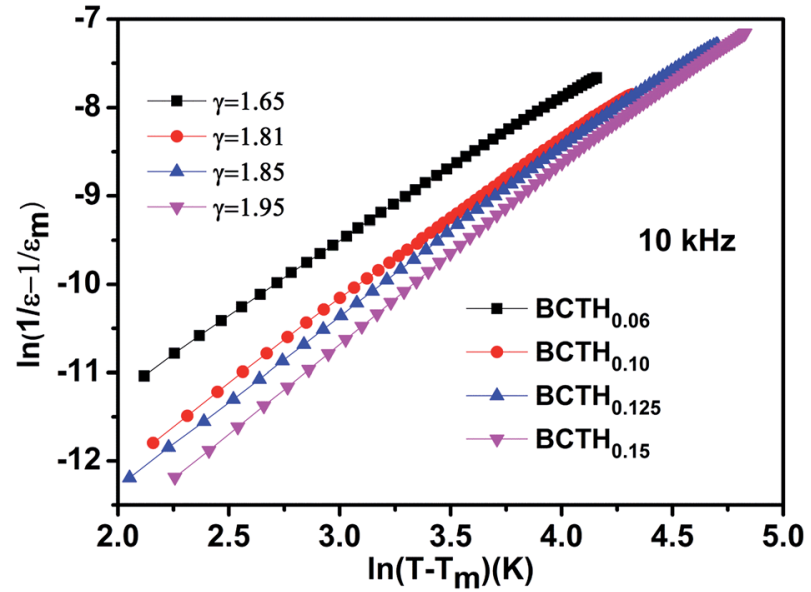

Fig. 3 Plot of $\ln \left(1 / \varepsilon-1 / \varepsilon_{m}\right)$ as a function of $\ln \left(T-T_{m}\right)$ for the $\mathrm{BCTH}_{x}$ ceramics at $10000 \mathrm{~Hz}$.

temperature also influence the diffuseness of phase transition of $\mathrm{BaTiO}_{3}$-based ceramics. ${ }^{41}$

The heat capacity $\left(C_{\mathrm{p}}\right)$ of $\mathrm{BCTH}_{x}$ ceramics is displayed in Fig. 4. The obvious heat flow peak is only observed in $\mathrm{BCTH}_{0.06}$ compound. That implies the diffuseness weakens the heat flow peak in other three ceramics. Obviously, $C_{\mathrm{p}}$ increases with increasing temperature, our data are in good agreement with the previous results on other $\mathrm{BaTiO}_{3}$-based ceramics. ${ }^{5,20}$ In order to evaluate the EC effect of $\mathrm{BCTH}_{x}$ ceramics, the $P-E$ hysteresis loops were measured at different temperature at $10 \mathrm{~Hz}$. Fig. 5 displays the $P-E$ hysteresis loops of $\mathrm{BCTH}_{x}$ ceramics at three different temperatures. Both polarization and coercive field decrease as the temperature increases. The $P-E$ hysteresis loops indicate these ceramics are ferroelectric below Curie temperature. The temperature is higher than its Curie temperature, the $P-E$ hysteresis loops shrink to an approximate line, implies the nature of paraelectric feature. The inset of Fig. 5(a) shows the pinched $P-E$ hysteresis loop at low electric field of $3 \mathrm{kV} \mathrm{cm}^{-1}$. From Fig. 5(d), one can see that the $\mathrm{BCTH}_{0.15}$

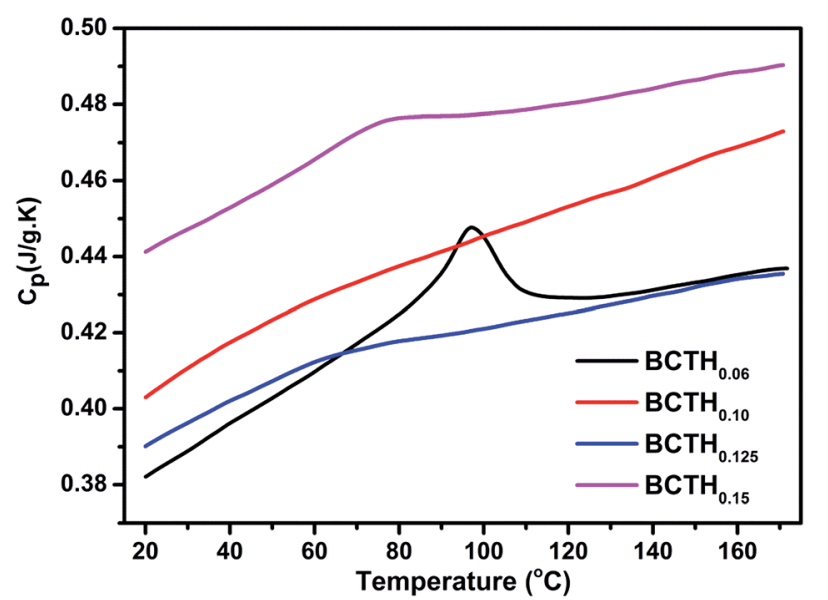

Fig. 4 The heat capacity $\left(C_{p}\right)$ as a function of temperature of $B C T H_{x}$ ceramics. 

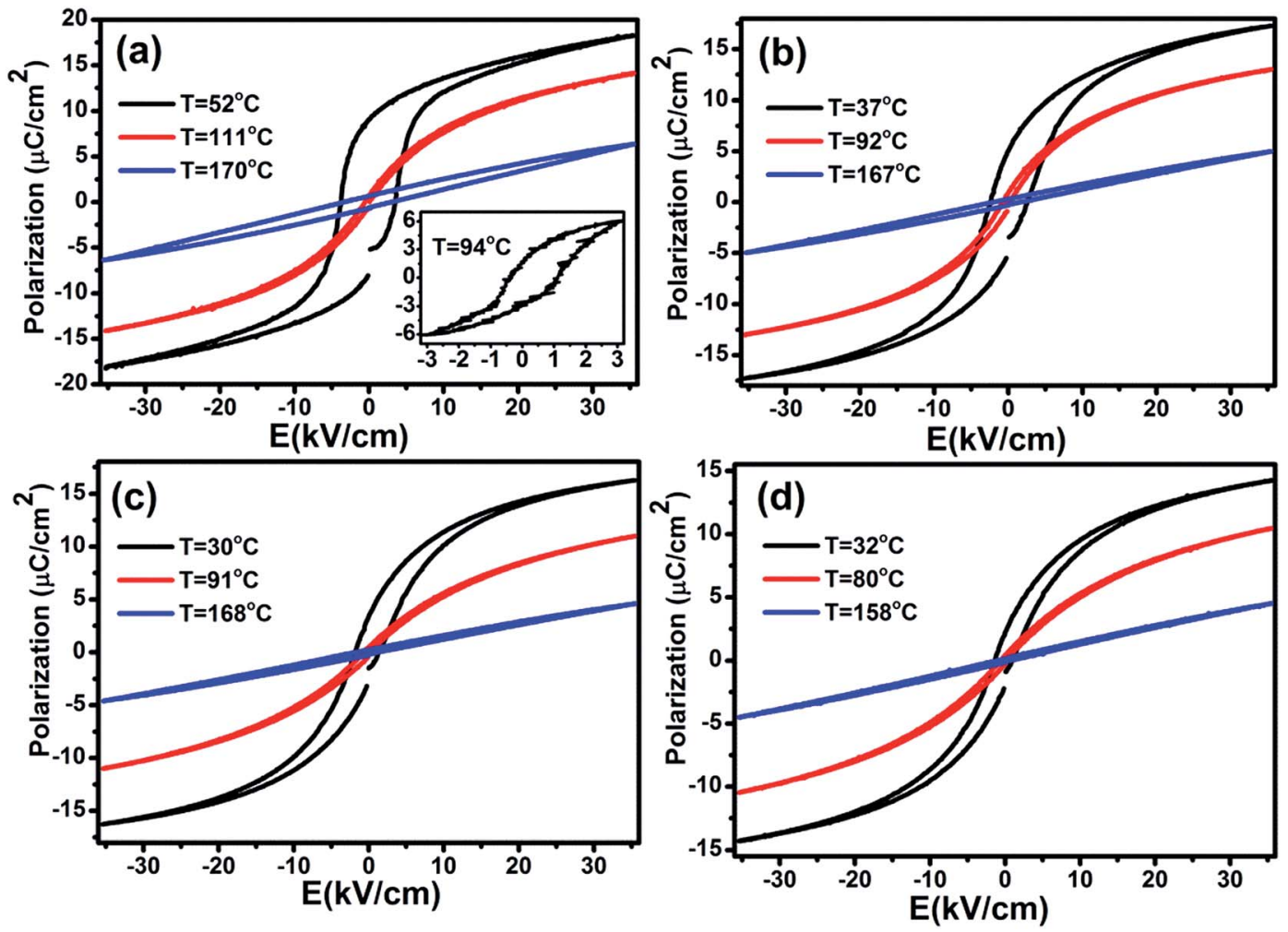

Fig. 5 The $P-E$ loops of $\mathrm{BCTH}_{x}$ (a) $x=0.06$, (b) $x=0.10$, (c) $x=0.125$, (d) $x=0.15$ ceramics under electric field of $35 \mathrm{kV} \mathrm{cm}^{-1}$. The inset: the pinched $P-E$ loops of $\mathrm{BCTH}_{0.06}$ under electric field of $3 \mathrm{kV} \mathrm{cm}^{-1}$ at $94{ }^{\circ} \mathrm{C}$.

ceramic shows relaxor-like feature, which agrees well with dielectric permittivity results. It is also observed that both polarization and coercive field decrease with increasing of $\mathrm{Hf}$ content. The $P-T$ curves of $\mathrm{BCTH}_{x}$ ceramics under various electric fields are shown in Fig. 6. One can see that large polarization value is induced by large external electric field at
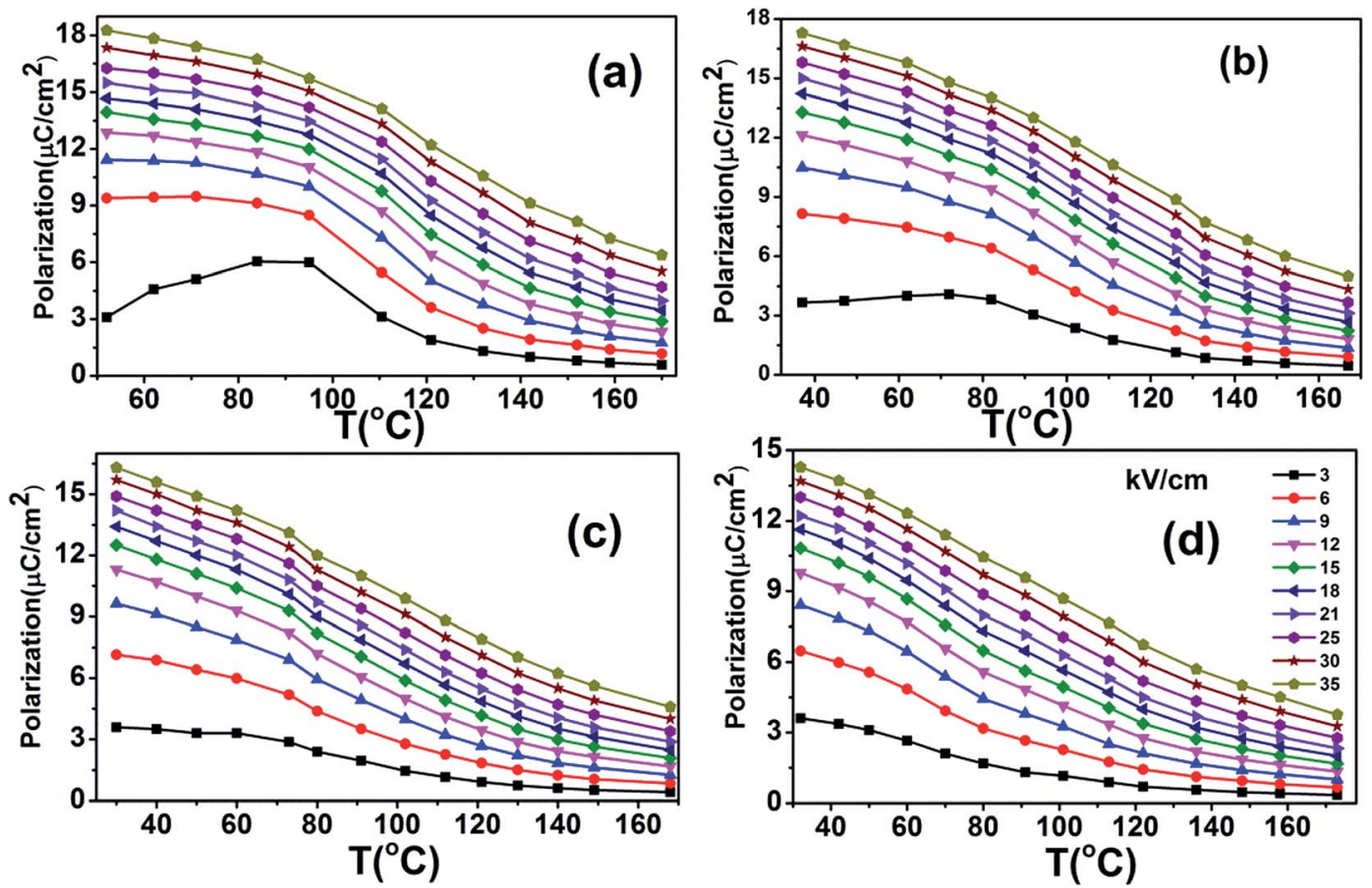

Fig. 6 The $P-T$ curves of $\mathrm{BCTH}_{x}$ (a) $x=0.06$, (b) $x=0.10$, (c) $x=0.125$, (d) $x=0.15$ ceramics at various electric field. 

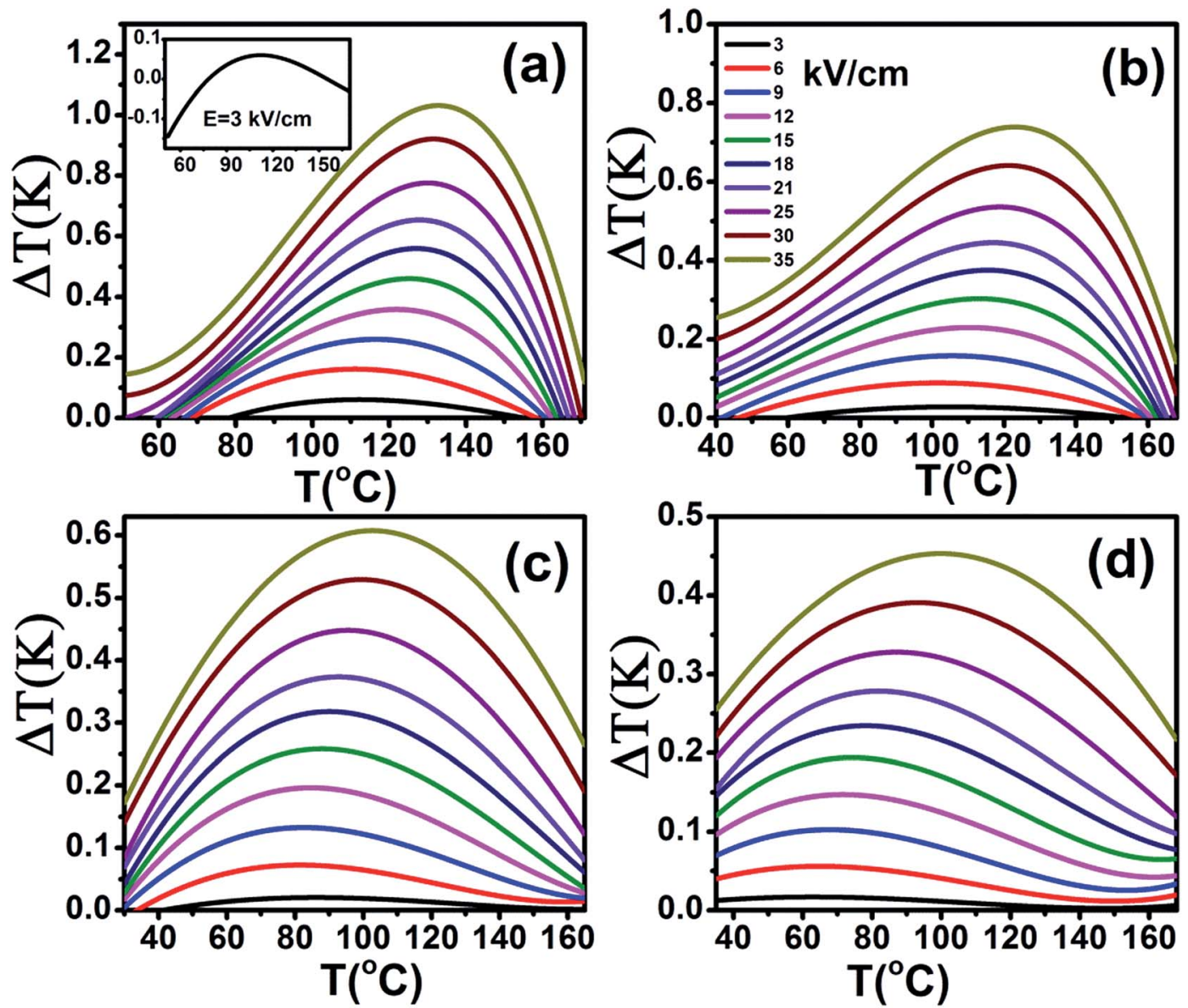

Fig. 7 Electrocaloric temperature change $(\Delta T)$ as a function of temperature of $\mathrm{BCTH}_{x}(\mathrm{a}) x=0.06$, (b) $x=0.10$, (c) $x=0.125$, (d) $x=0.15$ ceramics at various electric fields. The inset: electrocaloric temperature change $(\Delta T)$ of $B C T H_{0.06}$ at $3 \mathrm{kV} \mathrm{cm}^{-1}$.

the same temperature. The value of polarization decreases with increasing temperature. However, the polarization of $\mathrm{BCTH}_{0.06}$ ceramic starts to increase with increasing of temperature and then decreases at $3 \mathrm{kV} \mathrm{cm}^{-1}$, as seen in Fig. 6(a). This result can be expected to obtain negative EC effect.

According to the thermodynamics Maxwell relation, the adiabatic temperature change $\Delta T$ and isothermal entropy change $\Delta S$ are calculated by the temperature dependence of polarization by: ${ }^{2}$

$$
\begin{gathered}
\Delta T=-\frac{T}{\rho C_{\mathrm{p}}} \int_{E_{1}}^{E_{2}}\left(\frac{\partial \mathrm{P}}{\partial \mathrm{T}}\right)_{E} \mathrm{~d} E \\
\Delta S=-\frac{1}{\rho} \int_{E_{1}}^{E_{2}}\left(\frac{\partial \mathrm{P}}{\partial \mathrm{T}}\right)_{E} \mathrm{~d} E
\end{gathered}
$$

where $\rho$ is the density of ceramic, $E_{1}\left(E_{1}=0 \mathrm{kV} \mathrm{cm}^{-1}\right)$ and $E_{2}$ are the initial and final external electric field, respectively. The heat capacity $C_{\mathrm{p}}$ shows the temperature-dependent thermal properties. Previous studies ${ }^{3}$ suggested that the usage of constant heat capacity can obtain consistent EC value via indirect and direct methods. Here, the zero-field heat capacity $C_{\mathrm{p}}$ at room temperature is chosen to calculate the EC temperature change. The heat capacity $C_{\mathrm{p}}$ is $0.38,0.40,0.39$ and $0.44 \mathrm{~J} \mathrm{~g}^{-1} \mathrm{~K}^{-1}$ for the ceramic with $x=0.06,0.10,0.125$, and 0.15 , respectively. The densities of these ceramics are 5.72, $5.81,5.92$ and $5.93 \mathrm{~g} \mathrm{~cm}^{-3}$ for $x=0.06,0.10,0.125$, and 0.15 , respectively. Then, the $(\partial P /$ $\partial T)_{E}$ curves are obtained from the $P-E$ hysteresis loops measured at different temperatures and are fitted with a fourth order polynomial equation.

The adiabatic temperature change $\Delta T$ (in Fig. 7) and isothermal entropy change $\Delta S$ (in Fig. 8) in $\mathrm{BCTH}_{x}$ ceramics are obtained at various electric fields. It is found that negative EC effect is observed at $3 \mathrm{kV} \mathrm{cm}^{-1}$ in $\mathrm{BCTH}_{0.06}$ ceramic, as shown in the inset of Fig. 7(a). Negative EC effect can be attributed to the pinched ferroelectric hysteresis loops induced by the existence of multiphase. ${ }^{42}$ Large EC values are obtained at higher electric field in all ceramics. However, at higher temperature, the ceramic becomes more leaky and readily breakdown. The highest electric field of $35 \mathrm{kV} \mathrm{cm}^{-1}$ has been applied for the four ceramics at measured temperature. Table 1 and Fig. 7 show that the largest EC values at $35 \mathrm{kV} \mathrm{cm}^{-1}$ are $1.03 \mathrm{~K}$ for $\mathrm{BCTH}_{0.06}, 0.74$ $\mathrm{K}$ for $\mathrm{BCTH}_{0.10}, 0.61 \mathrm{~K}$ for $\mathrm{BCTH}_{0.125}$, and $0.45 \mathrm{~K}$ for $\mathrm{BCTH}_{0.15}$, respectively, all occurring near the ferroelectric-paraelectric phase transition. The isothermal entropy change $\Delta S$ shows the same change trend as the electrocaloric temperature change $\Delta T$. The corresponding isothermal entropy change $\Delta S$ are $0.98 \mathrm{~J}$ 

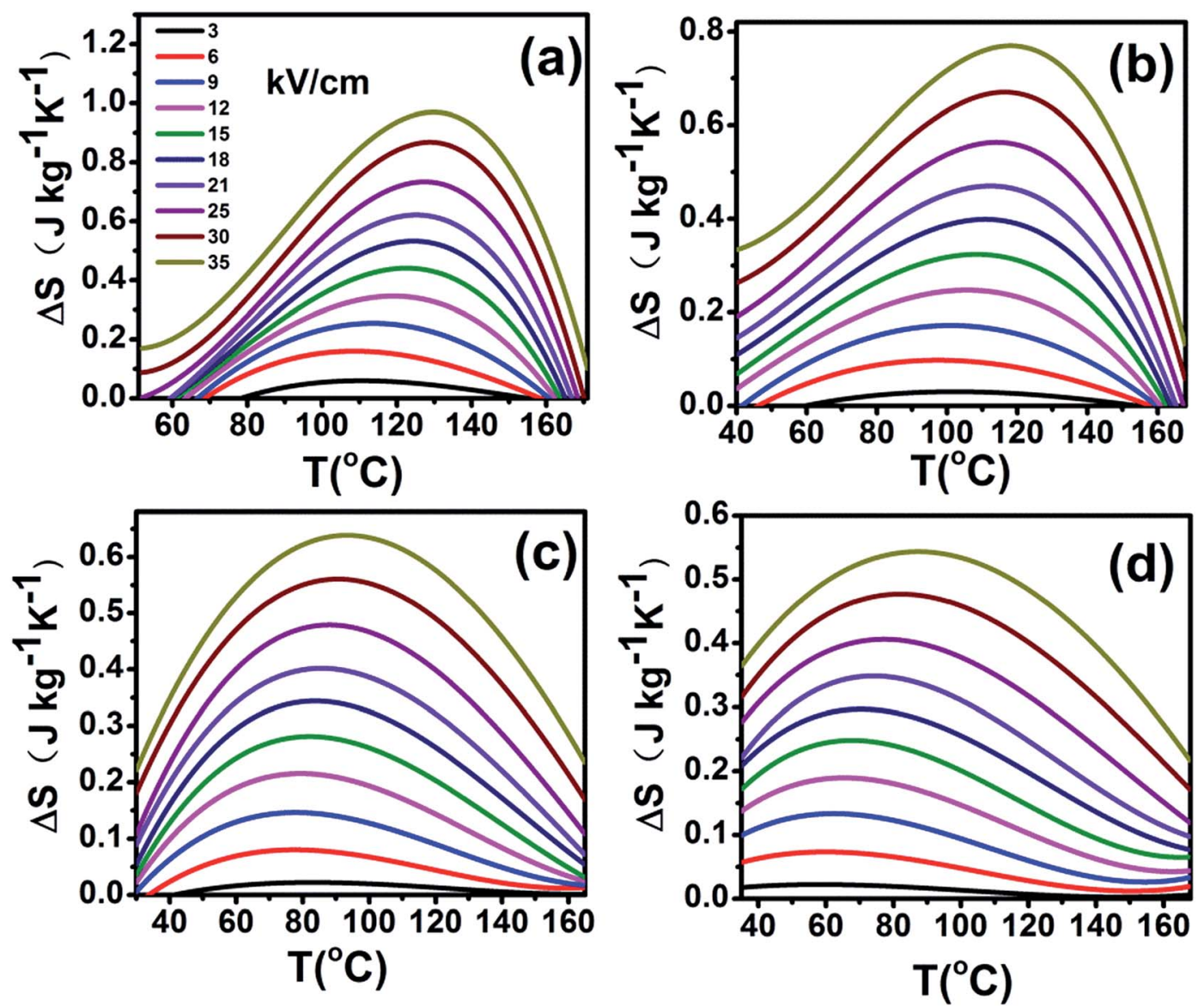

Fig. 8 Entropy change $(\Delta T)$ as a function of temperature of $\mathrm{BCTH}_{x}(\mathrm{a}) x=0.06$, (b) $x=0.10,(\mathrm{c}) x=0.125$, (d) $x=0.15$ ceramics at various electric fields.

Table 1 The temperature $\left(T_{\text {Ecmax }}\right)$ where the maximum EC value is achieved, the EC temperature change $\Delta T$ at $T_{\text {Ecmax }}, T_{\text {Ecmax }}-20$, and $T_{\text {Ecmax }}+20$ at $35 \mathrm{kV} \mathrm{cm}^{-1}, 21 \mathrm{kV} \mathrm{cm}^{-1}$, and $9 \mathrm{kV} \mathrm{cm}^{-1}$

\begin{tabular}{llllll}
\hline Ceramic & $\begin{array}{l}E \\
\left(\mathrm{kV} \mathrm{cm}^{-1}\right)\end{array}$ & $\begin{array}{l}T_{\text {Ecmax }} \\
\left({ }^{\circ} \mathrm{C}\right)\end{array}$ & $\begin{array}{l}\Delta T \\
(\mathrm{~K})\end{array}$ & $\begin{array}{l}\Delta T \\
\left(T_{\text {Ecmax }}-20\right)\end{array}$ & $\begin{array}{l}\Delta T \\
\left(T_{\text {Ecmax }}+20\right)\end{array}$ \\
\hline $\mathrm{BCTH}_{0.06}$ & 35 & 133 & 1.03 & 0.89 & 0.81 \\
& 21 & 128 & 0.65 & 0.55 & 0.50 \\
& 9 & 117 & 0.26 & 0.22 & 0.21 \\
$\mathrm{BCTH}_{0.10}$ & 35 & 123 & 0.74 & 0.67 & 0.64 \\
& 21 & 117 & 0.44 & 0.40 & 0.38 \\
& 9 & 106 & 0.16 & 0.14 & 0.14 \\
$\mathrm{BCTH}_{0.125}$ & 35 & 103 & 0.61 & 0.57 & 0.57 \\
& 21 & 93 & 0.37 & 0.34 & 0.35 \\
$\mathrm{BCTH}_{0.15}$ & 9 & 83 & 0.13 & 0.12 & 0.12 \\
& 21 & 100 & 0.45 & 0.43 & 0.43 \\
& 9 & 82 & 0.28 & 0.26 & 0.26 \\
& & 68 & 0.10 & 0.09 & 0.09
\end{tabular}

$\mathrm{kg}^{-1} \mathrm{~K}^{-1}$ for $\mathrm{BCTH}_{0.06}, 0.77 \mathrm{~J} \mathrm{~kg}^{-1} \mathrm{~K}^{-1}$ for $\mathrm{BCTH}_{0.10}, 0.64 \mathrm{~J} \mathrm{~kg}^{-1}$ $\mathrm{K}^{-1}$ for $\mathrm{BCTH}_{0.125}$, and $0.54 \mathrm{~J} \mathrm{~kg}^{-1} \mathrm{~K}^{-1}$ for $\mathrm{BCTH}_{0.15}$, respectively, under the electric field of $35 \mathrm{kV} \mathrm{cm}^{-1}$, as displayed in Fig. 8. It is well known that both large EC value and high EC strength are beneficial for the application of cooling device. The temperature of maximum $\Delta T$ and EC strength at various electric fields are displayed in Fig. 9(a) and (b). For BCHT $_{0.06}$ ceramic, the EC temperature change $\Delta T$ of $0.36 \mathrm{~K}$ occurs at $121^{\circ} \mathrm{C}$ under electric field of $12 \mathrm{kV} \mathrm{cm}{ }^{-1}$, while $\Delta T$ increases to $1.03 \mathrm{~K}$ occurring at $132{ }^{\circ} \mathrm{C}$ as electric field increases to $35 \mathrm{kV} \mathrm{cm}^{-1}$. Similar results are observed for other three ceramics, see Fig. 7. Obviously, the temperature at which the maximum $\Delta T$ is obtained for all the ceramics shifts to higher temperature with increasing of the electric filed, see Fig. 9(a). Such phenomenon indicates that the Curie temperature of these ceramics is shifted to higher temperature under higher electric field, which agrees well with previous works on $0.71 \mathrm{PbMg}_{1 / 3} \mathrm{Nb}_{2 / 3} \mathrm{O}_{3}-0.29 \mathrm{PbTiO}_{3}$ single crystal, ${ }^{34}$ BaTiO $_{3}$ single crystals ${ }^{3,43}$ and BaTiO $_{3}$-based ceramics. $^{\mathbf{4 4 , 4 5}}$ The elevated Curie temperature under higher electric field is attributed to the electric-induced phase transition or change in domain configuration. ${ }^{45}$

The EC strength of all ceramics increases sharply below 15 $\mathrm{kV} \mathrm{cm}^{-1}$, as shown in Fig. 9(b). The enhanced EC strength at low electric field is dominantly attributed to the entropy contribution of non-180 domain switching. ${ }^{46,47}$ Above $15 \mathrm{kV} \mathrm{cm}^{-1}$, the EC strength is nearly constant. Such results suggest that high EC strength can be obtained at relative low electric field. Higher electric field may induce electrical fatigue, mechanical cracks and Joule heating, which are not desirable for practical 

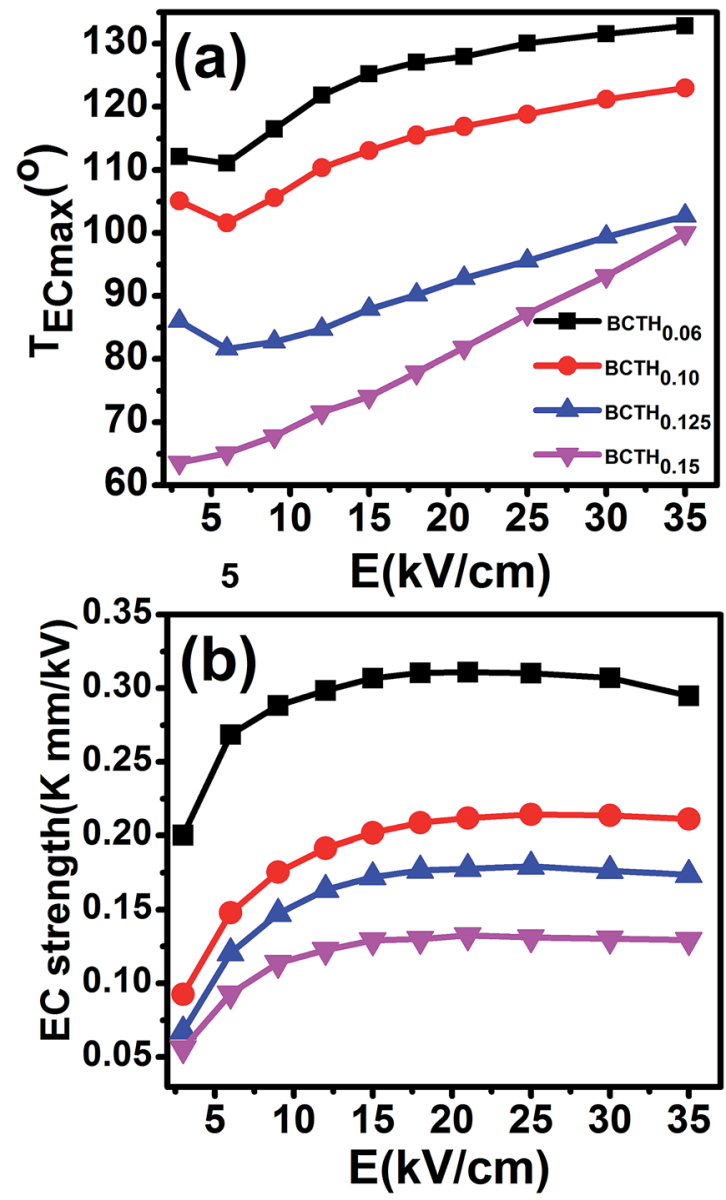

Fig. 9 The temperature of maximum $\Delta T$ (a) and EC strength (b) at various electric fields.

applications. The polarization of $\mathrm{BCTH}_{0.06}$ ceramic is saturated easily at a relatively low electric field of $9 \mathrm{kV} \mathrm{cm}{ }^{-1}$. However, more diffusive second order phase transition is induced, along with reduced EC strength with increasing of electric field. For example, for $\mathrm{BCTH}_{0.06}$ ceramic, the EC strength is up to $0.31 \mathrm{~K}$ $\mathrm{mm} \mathrm{kV}{ }^{-1}$ at $21 \mathrm{kV} \mathrm{cm}^{-1}$, it decreases to $0.29 \mathrm{~K} \mathrm{~mm} \mathrm{kV}^{-1}$ under an electric field of $35 \mathrm{kV} \mathrm{cm}^{-1}$. The EC strength is larger than most of lead-free ceramics ${ }^{24,25,27}$ and even lead-based ceramic. ${ }^{16}$ For $\mathrm{BCTH}_{0.06}$ ceramic, the EC values are $1.03 \mathrm{~K}$ at $133^{\circ} \mathrm{C}, 0.89 \mathrm{~K}$ at $113^{\circ} \mathrm{C}$ and $0.81 \mathrm{~K}$ at $153^{\circ} \mathrm{C}$ under electric filed of $35 \mathrm{kV} \mathrm{cm}^{-1}$, respectively, as shown in Table 1 and Fig. 7(a). Obviously, the decrease in $\Delta T$ above the $T_{\text {Emax }}$ temperature is more significant than that below the $T_{\mathrm{Emax}}$ temperature. This implies that superior EC effect can be obtained below Curie temperature. The responding EC strength is $0.29 \mathrm{~K} \mathrm{~mm} \mathrm{kV}^{-1}, 0.25 \mathrm{~K} \mathrm{~mm}$ $\mathrm{kV}^{-1}$ and $0.23 \mathrm{~K} \mathrm{~mm} \mathrm{kV}^{-1}$, respectively, at $35 \mathrm{kV} \mathrm{cm}^{-1}$. Both the EC value and EC strength decrease slightly below or above $20^{\circ} \mathrm{C}$ of EC peak temperature. The EC strength is $0.23-0.29 \mathrm{~K} \mathrm{~mm}$ $\mathrm{kV}^{-1}$ at the temperature span of $40^{\circ} \mathrm{C}$, which displays a relatively broad EC temperature span. The EC strength of $\mathrm{BCTH}_{0.15}$ is nearly constant, although this value is only $0.13 \mathrm{~K} \mathrm{~mm} \mathrm{kV}^{-1}$ at the range of $40{ }^{\circ} \mathrm{C}$. For these ceramics, the maximum temperature span becomes broader with increasing Hf content, which can be attributed to the diffuseness character of the ceramics with higher Hf doping level. Our dielectric and heat capacity datas also confirm the diffuseness character with increasing $\mathrm{Hf}$ content. Unfortunately, both EC value and EC strength decrease dramatically in the ceramics with diffuse phase transition.

\section{Conclusions}

In summary, the $\mathrm{BCTH}_{x}$ ceramics are fabricated using solid state reaction route. We systematically investigated their EC effect of these four ceramics as a function of temperature and electric field using indirect method based on thermodynamics Maxwell relation. The $\mathrm{BCTH}_{0.06}$ ceramic displays a sharp ferroelectric-paraelectric phase transition, large EC value of $1.03 \mathrm{~K}$ at $35 \mathrm{kV} \mathrm{cm}^{-1}$ is reported, associated with a relatively broad EC temperature span. Under the electric field of 9 to $35 \mathrm{kV}$ $\mathrm{cm}^{-1}$, the EC strength is $0.29-0.31 \mathrm{~K} \mathrm{~mm} \mathrm{kV}^{-1}$, which are comparable to the best results of previous studies. With increasing $\mathrm{Hf}$ contents, the dielectric analysis shows that the ceramics display strong diffusive character. The $\mathrm{BCTH}_{0.15}$ ceramic has relative small EC strength $\left(0.10-0.13 \mathrm{~K} \mathrm{~mm} \mathrm{kV}^{-1}\right)$ and exhibit a broader EC temperature span. The decreasing EC strength and broad EC temperature span are attributed to the nature of diffuse feature of ceramic. In addition, the temperature of EC peak shifts to higher temperature as the electric field increases, which suggests that electric field can be an useful tool to tune the temperature of EC peak. Our results indicate that compositional modification of $\mathrm{BaTiO}_{3}$ ceramics may offer a promising route for designing potential EC materials.

\section{Acknowledgements}

This work was supported by National Science Foundation of China (NSFC No. 51372195, 41372055), fundamental Research Funds for Central Universities (2013JDGZ03), the CSS project (Grant No. YK2015-0602006) and Grant No. IRT13034. X. J. Lou would like to thank the "One Thousand Youth Talents" program for support.

\section{References}

1 T. Correia and Q. Zhang, Electrocaloric Materials, Springer, 2014.

2 A. Mischenko, Q. Zhang, J. Scott, R. Whatmore and N. Mathur, Science, 2006, 311(5765), 1270-1271.

3 X. Moya, E. Stern-Taulats, S. Crossley, D. González-Alonso, S. Kar-Narayan, A. Planes, L. Mañosa and N. D. Mathur, Adv. Mater., 2013, 25(9), 1360-1365.

4 G. Zhang, X. Zhang, H. Huang, J. Wang, Q. Li, L.-Q. Chen and Q. Wang, Adv. Mater., 2016, 28(24), 4811-4816.

5 B. Asbani, J.-L. Dellis, A. Lahmar, M. Courty, M. Amjoud, Y. Gagou, K. Djellab, D. Mezzane, Z. Kutnjak and M. El Marssi, Appl. Phys. Lett., 2015, 106(4), 042902.

6 Y. Bai, G.-P. Zheng and S.-Q. Shi, Mater. Res. Bull., 2011, 46(11), 1866-1869.

7 Z. Luo, D. Zhang, Y. Liu, D. Zhou, Y. Yao, C. Liu, B. Dkhil, X. Ren and X. Lou, Appl. Phys. Lett., 2014, 105(10), 102904. 
8 B. Peng, H. Fan and Q. Zhang, Adv. Funct. Mater., 2013, 23(23), 2987-2992.

9 S. Lu, B. Rožič, Q. Zhang, Z. Kutnjak and B. Neese, Appl. Phys. Lett., 2011, 98(12), 122906.

10 G. Zhang, Q. Li, H. Gu, S. Jiang, K. Han, M. R. Gadinski, M. A. Haque, Q. Zhang and Q. Wang, Adv. Mater., 2015, 27(8), 1450-1454.

11 W. Geng, Y. Liu, X. Meng, L. Bellaiche, J. F. Scott, B. Dkhil and A. Jiang, Adv. Mater., 2015, 27(20), 3165-3169.

12 M. Ye, T. Li, Q. Sun, Z. Liu, B. Peng, C. Huang, P. Lin, S. Ke, X. Zeng, X. Peng, L. Chen and H. Huang, J. Mater. Chem. C, 2016, 4(16), 3375-3378.

13 H. Khassaf, J. V. Mantese, N. Bassiri-Gharb, Z. Kutnjak and S. P. Alpay, J. Mater. Chem. C, 2016, 4(21), 4763-4769.

14 H. Kaddoussi, Y. Gagou, A. Lahmar, J. Belhadi, B. Allouche, J.-L. Dellis, M. Courty, H. Khemakhem and M. El Marssi, Solid State Commun., 2015, 201, 64-67.

15 F. Han, Y. Bai, L.-J. Qiao and D. Guo, J. Mater. Chem. C, 2016, 4(9), 1842-1849.

16 B. Rožič, M. Kosec, H. Uršič, J. Holc, B. Malič, Q. Zhang, R. Blinc, R. Pirc and Z. Kutnjak, J. Appl. Phys., 2011, 110(6), 064118.

17 Z. Y. Jiang, X. C. Zheng and G. P. Zheng, RSC Adv., 2015, 5(76), 61946-61954.

18 G. Zhang, Z. Chen, B. Fan, J. Liu, M. Chen, M. Shen, P. Liu, Y. Zeng, S. Jiang and Q. Wang, APL Mater., 2016, 4(6), 064103.

19 G. Singh, I. Bhaumik, S. Ganesamoorthy, R. Bhatt, A. Karnal, V. Tiwari and P. Gupta, Appl. Phys. Lett., 2013, 102(8), 082902. 20 X. Wang, F. Tian, C. Zhao, J. Wu, Y. Liu, B. Dkhil, M. Zhang, Z. Gao and X. Lou, Appl. Phys. Lett., 2015, 107(25), 252905.

21 X. S. Qian, H. J. Ye, Y. T. Zhang, H. Gu, X. Li, C. Randall and Q. Zhang, Adv. Funct. Mater., 2014, 24(9), 1300-1305.

22 M. Zannen, A. Lahmar, B. Asbani, H. Khemakhem, M. El Marssi, Z. Kutnjak and M. Es Souni, Appl. Phys. Lett., 2015, $107(3), 032905$.

23 F. Le Goupil, J. Bennett, A.-K. Axelsson, M. Valant, A. Berenov, A. J. Bell, T. P. Comyn and N. M. Alford, Appl. Phys. Lett., 2015, 107(17), 172903.

24 F. Le Goupil and N. M. Alford, APL Mater., 2016, 4(6), 064104.

25 J. Koruza, B. Rožič, G. Cordoyiannis, B. Malič and Z. Kutnjak, Appl. Phys. Lett., 2015, 106(20), 202905.

26 W. Liu and X. Ren, Phys. Rev. Lett., 2009, 103(25), 257602.
27 Y. Bai, X. Han and L. Qiao, Appl. Phys. Lett., 2013, 102(25), 252904.

28 Y. Zhou, Q. Lin, W. Liu and D. Wang, $R S C A d v .$, 2016, 6(17), 14084-14089.

29 J. Peräntie, H. N. Tailor, J. Hagberg, H. Jantunen and Z.-G. Ye, J. Appl. Phys., 2013, 114(17), 174105.

30 M. Quintero, L. Ghivelder, F. Gomez-Marlasca and F. Parisi, Appl. Phys. Lett., 2011, 99(23), 232908.

31 X. Zhang, L. Wu, S. Gao, J. Liu, B. Xu, Y. Xia, J. Yin and Z. Liu, AIP Adv., 2015, 5(4), 047134.

32 B. Rožič, M. Kosec, H. Uršič, J. Holc, B. Malič, Q. M. Zhang, R. Blinc, R. Pirc and Z. Kutnjak, J. Appl. Phys., 2011, 110(6), 064118.

33 N. Novak, R. Pirc and Z. Kutnjak, Phys. Rev. B: Condens. Matter Mater. Phys., 2013, 87(10), 104102.

34 L. Luo, M. Dietze, C.-H. Solterbeck, M. Es-Souni and H. Luo, Appl. Phys. Lett., 2012, 101(6), 062907.

35 Y. P. Shi and A. K. Soh, Acta Mater., 2011, 59(14), 5574-5583.

36 S. Anwar, P. R. Sagdeo and N. P. Lalla, Solid State Commun., 2006, 138(7), 331-336.

37 X. G. Tang, K. H. Chew and H. L. W. Chan, Acta Mater., 2004, 52(17), 5177-5183.

38 C. Zhao, W. Wu, H. Wang and J. Wu, J. Appl. Phys., 2016, 119(2), 024108.

39 K. Uchino and S. Nomura, Ferroelectrics, 1982, 44(1), 55-61.

40 X. G. Tang, K. H. Chew and H. L. W. Chan, Acta Mater., 2004, 52(17), 5177-5183.

41 P. Mishra and P. Sonia Kumar, J. Alloys Compd., 2012, 545, 210-215.

42 B. Xu, C. Paillard, B. Dkhil and L. Bellaiche, Phys. Rev. B: Condens. Matter Mater. Phys., 2016, 94(14), 140101.

43 N. Novak, R. Pirc and Z. Kutnjak, Ferroelectrics, 2014, 469(1), 61-66.

44 M. Sanlialp, V. V. Shvartsman, M. Acosta, B. Dkhil and D. C. Lupascu, Appl. Phys. Lett., 2015, 106(6), 062901.

45 H. Guo, B. K. Voas, S. Zhang, C. Zhou, X. Ren, S. P. Beckman and X. Tan, Phys. Rev. B: Condens. Matter Mater. Phys., 2014, 90(1), 014103.

46 S. Gupta and S. Priya, Appl. Phys. Lett., 2013, 102(1), 012906. 47 Q. M. Zhang, H. Wang, N. Kim and L. E. Cross, J. Appl. Phys., 1994, 75(1), 454-459. 